Analytica Chimica Acta, 114 (1980) 235-246

() Elsevier Scientific Publishing Company, Amsterdam - Printed in The Netherlands

\title{
A MODELLING APPROACH TO ESTABLISH EXPERIMENTAL PARAMETERS OF A FLOW-THROUGH TITRATION
}

\author{
H. F. R. REIJNDERS and J. J. VAN STADEN
}

National Institute of Public Health, Bilthoven (The Netherlands)

G. H. B. EELDERINK

Control Engineering Laboratory, Delfit University of Technology (The Netherlands)

\section{B. GRIEPINK*}

Laboratory for Analytical Chemistry, University of Utrecht, Croesestraat $77^{a}, 3522 A D$ Utrecht (The Netherlands)

(Received 21st August 1979)

\section{SUMMARY}

A flow-through titrimeter with optical detection and the flow-through titration of sulphate have been studied by using control engineering methods. Qualitative chemical descriptions and systems analysis yield a model covering different precipitation rates of barium sulphate. The validity of the model is proved by comparing simulated and real experiments. Possible uses of the model are indicated. The signal of the titrimeter is shown to be independent of dilution and turbidity, because of the special detection arrangement.

Many analytical systems can be described in control engineering terms [1-3]. Computer simulation on a mathematical model of such a system reduces the number of experiments required to develop the optimal analytical system. Moreover, the mathematical model itself is a help in understanding the processes involved in the analysis.

Recently a flow-through titration of sulphate was described $[4,5]$. To study this titration system in greater detail, it was decided to establish a mathematical model which in turn could help to find the optimal settings of several parameters involved. The titrimeter has been described elsewhere [6, 7]. Figure 1 presents its main parts; the sample from a turntable is mixed with a setpoint solution [consisting of a barium sulphate suspension, barium ions and dimethylsulphonazo-III (DMSA)] and fed to a titration cell $(8 \mathrm{ml})$. The excess of solution is pumped to waste. The reaction involved is: Ba(DMSA) $+\mathrm{SO}_{4}{ }^{2-} \rightleftharpoons \mathrm{BaSO}_{4}+\mathrm{DMSA}^{2-}$. The bulb $\mathrm{L}$ emits white light which passes alternately through two interference filters $f_{1}$ and $f_{2}$ (yielding wavelengths $\lambda_{1}$ and $\lambda_{2}$, respectively) mounted on a spinning wheel. From the data shown in Fig. 2 one of the wavelengths $\lambda_{1}$ is chosen at the isosbestic point in which the transmittance is not affected by the chemical reaction; the transmittance at the other wavelength $\lambda_{2}$ depends on the concentrations of Ba(DMSA) and 


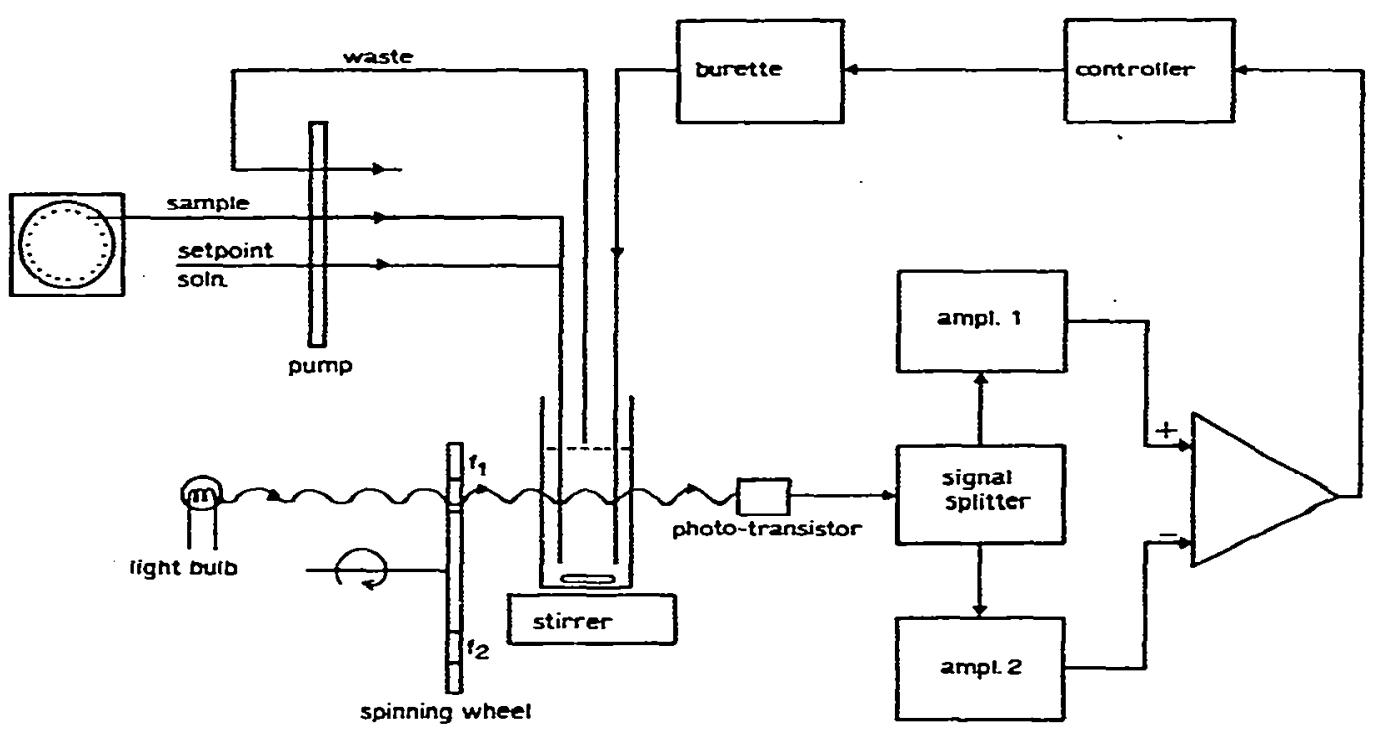

Fig. 1. Scheme of the flow-through titrimeter.

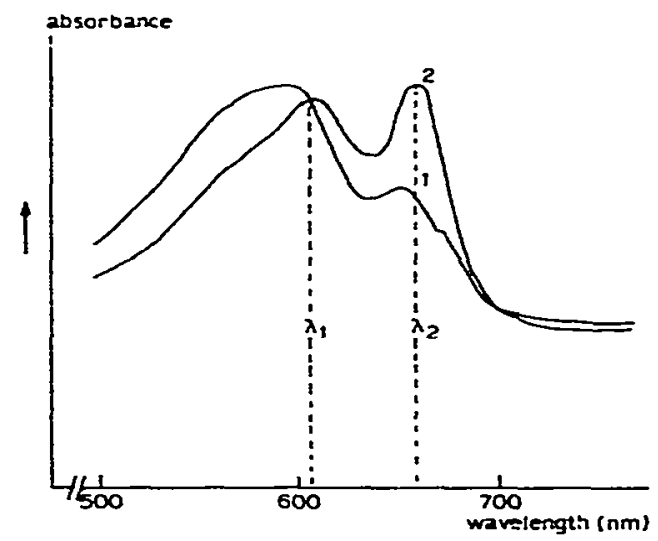

Fig. 2. Absorption spectra of DMSA (1) and Ba(DMSA) (2).

DMSA $^{2-}$. The transmittances at both wavelengths are detected by a single photo-transistor. The resulting signals are subtracted, yielding a signal $U$ after amplification.

In the following paragraphs, it is proved that this procedure makes the signal itself independent of the turbidity in the solution and also of dilution by any other solution. However, dilution of a system in chemical equilibrium may cause a shift in this equilibrium which influences the signal. The influence of this shift on the system may be calculated.

The first part of this paper describes a mathematical treatment of the 
system and a calculation of the influence of a shift in the $\mathrm{Ba}$ (DMSA)sulphate ratio. The second part deals with the mathematical model of the complete flow-through titration of sulphate.

\section{MODELLING OF THE TITRIMETER}

The model to be defined will describe the way in which a number of factors influences the signal $U$ of the titrimeter. A functional block scheme (Fig. 3) of the device is first set up in which those factors are taken into account which relate to the physical and chemical processes involved between the initial radiation $I_{0}$ and the final signal $U$. The value of the signal $U$ depends on several factors: the turbidity, the concentrations of the species involved, the radiation intensity, the sensitivity of the photodetector, etc. By a proper setting of amplifications and a correct selection of wavelengths, the signal $U$ equals zero in the setpoint situation. In this way a number of influences are eliminated.

In a first approach each effect is described separately in terms of the transfer functions of the several blocks. A transfer function is defined here as the mathematical expression of the relation between input and output of a block. Sometimes the transfer function can be measured for each block, but mostly it can be measured only for a larger part of a loop, comprising several individual transfer functions. Therefore transfer functions cannot be established solely by measurement, but also must be derived from chemical and physical reasoning. A list of symbols that will be used is given in Table 1.

The transfer function $H_{\mathrm{f}}$ of the filters is defined as: $H_{\mathrm{f}}=I_{\mathrm{f}} / I_{\mathrm{0}}$. As previously described [7] the turbidity causes a transfer function $H_{t}$ of the form:

$H_{\mathrm{t}}=I_{\mathrm{t}} / I_{\mathrm{f}}=\exp \left(-n \pi r^{2} Q_{\lambda, \mathrm{r}} l\right)$

The transfer function $H_{c}$ for the transmittance of the coloured species is given by the Lambert-Beer law:

$H_{\mathrm{c}}=I / I_{\mathrm{t}}=\exp (-\epsilon c l)$

The transfer functions of the detector and amplifier are, respectively,

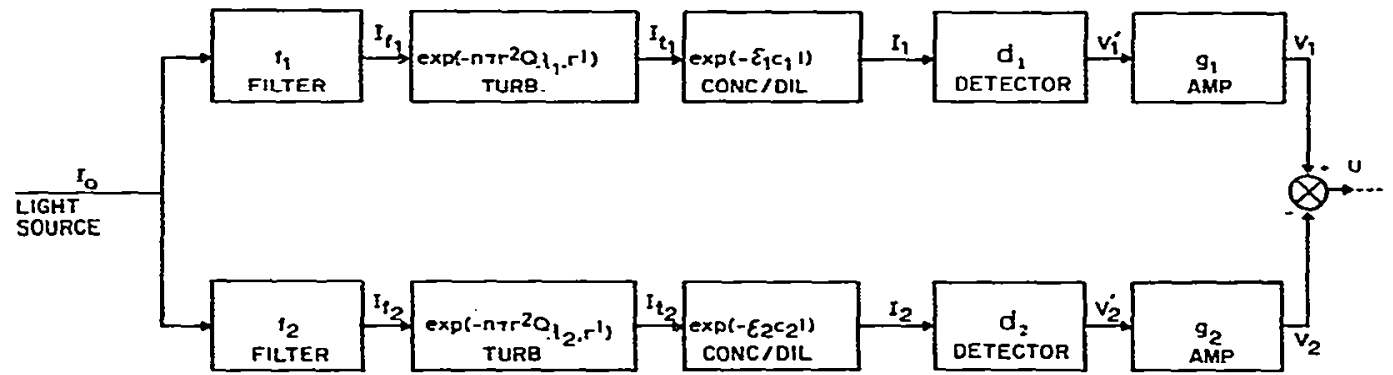

Fig. 3. Functional block scheme of the titrimeter with transfer functions for each block. For simplicity the symbol $H$ is omitted from the blocks. 
TABLE 1

List of symbols used

\begin{tabular}{|c|c|c|c|}
\hline Symbol & Meaning & Symbol & Meaning \\
\hline $\boldsymbol{H}$ & $H(p)$ : transfer function in the & $\boldsymbol{I}$ & Intensity of the transmitted light \\
\hline & Lap & $\lambda$ & Wavelength \\
\hline & I saplace operator & $l$ & Optical pathlength of the titration \\
\hline & Total concentration of indicator & & \\
\hline$C_{\mathrm{SO}_{4}}$ & $\begin{array}{l}\text { Sulphate concentration in the } \\
\text { titration cell }\end{array}$ & $\begin{array}{l}m \\
n\end{array}$ & $\begin{array}{l}\text { Amount of indicator } \\
\text { Number of solid particles per }\end{array}$ \\
\hline $\mathrm{cSO}_{4}$ & Sulphate concentration in the & & volume \\
\hline$\epsilon$ & absorptivit & $r$ & $\begin{array}{l}\text { Scattering-efficiency fac } \\
\text { Radius of solid particle }\end{array}$ \\
\hline$I_{0}$ & Intensity of incident light & $\boldsymbol{U}$ & Output signal of the titrimeter \\
\hline$I_{\mathbf{f}}$ & $\begin{array}{l}\text { Intensity of the transmitted } \\
\text { light from an interference filter }\end{array}$ & $\boldsymbol{V}$ & $\begin{array}{l}\text { Signal at the end of a pathway of } \\
\text { the titrimeter }\end{array}$ \\
\hline$I_{\mathbf{t}}$ & $\begin{array}{l}\text { Intensity of transmitted light } \\
\text { from a turbid solution containing } \\
\text { light-absorbing species }\end{array}$ & $\begin{array}{l}V^{\prime} \\
v\end{array}$ & $\begin{array}{l}\text { Signal from the phototransistor } \\
\text { Volume of solution in the titration } \\
\text { cell }\end{array}$ \\
\hline
\end{tabular}

$H_{\mathrm{d}}=V^{\prime} / I=d$ and $H_{\mathrm{a}}=V / V^{\prime}=\mathrm{g}$. The transfer functions for each block are indicated in Fig. 3. The preceding equations yield for the signal $V$ in each of the pathways: $V=I_{0} H_{\text {tot }}$, in which $H_{\text {tot }}=H_{\mathrm{f}} H_{\mathrm{t}} H_{\mathrm{c}} H_{\mathrm{d}} H_{\mathrm{a}}$.

The device is set in such a way that in the setpoint situation the resulting signal $U$ equals zero, the signals in each pathway $\left(V_{1}\right.$ and $V_{2}$, respectively) being equal: $H_{\text {tot } 1}=H_{\text {tot2. }}$

The influences on the resulting signal $U$ of the subtraction photometric device of this kind [6] caused by small variations in the parameters of the several transfer functions are considered below. Some of the known properties [7] of subtraction photometry are simply mentioned; others are considered in more detail.

\section{Light intensity:}

Small voltage fluctuations of the bulb, causing small fluctuations in the relative spectral intensities, are of little importance in this system because only one bulb is involved and the wavelengths are selected close to each other. Thus spectral bias in $I_{0}$ is negligible and fluctuations are eliminated by subtraction of $V_{1}$ and $V_{2}$.

\section{Turbidity}

As already shown [7] the number of particles per volume affects the value of $V$. Thus from the equation $V=I_{0} H_{\text {tot }}$ :

$$
\begin{aligned}
& \mathrm{d} V / \mathrm{d} n=I_{0} \mathrm{~d} H_{\text {tot }} / \mathrm{d} n=I_{0}\left(\mathrm{~d} H_{\mathrm{tot}} / \mathrm{d} H_{\mathrm{t}}\right)=\left(\mathrm{d} H_{\mathrm{t}} / \mathrm{d} n\right)=I_{0} H_{\text {tot }}\left(I / H_{\mathrm{t}}\right)\left(\mathrm{d} H_{\mathrm{t}} / \mathrm{d} n\right) \\
& \text { where } \mathrm{d} H_{\mathrm{t}} / \mathrm{d} n=-\pi r^{2} Q_{\lambda, \mathrm{r}} l \exp \left(-n \pi r^{2} Q_{\lambda, \mathrm{r}} l\right)=K_{\mathrm{t}} H_{\mathrm{t}}
\end{aligned}
$$

If $K_{\mathrm{t}}$ is a constant defined as $K_{\mathrm{t}}=-\pi r^{2} Q_{\lambda, \mathrm{x}} l$, then $\mathrm{d} V=-K_{\mathrm{t}} I_{0} H_{\text {tot }} \mathrm{d} n$. 
The change $\mathrm{d} U$ in the final signal at point $U$ caused by a change of turbidity is expressed as:

$\mathrm{d} U / \mathrm{d} n=I_{0} H_{\text {tot }}\left(-K_{\mathrm{t} 1}+K_{\mathrm{t} 2}\right)$

It can reasonably be assumed that the scattering of light by solid particles in the case of the two close wavelengths 1 and 2 dues not differ measurably, thus $K_{\mathrm{t} 1}=K_{\mathrm{t} 2}$. Equation (4) shows that under the assumption made above turbidity does not affect the final signal at point $U$.

\section{Dilution}

Dilution, for example, by addition of a yolume $d v$ of titrant, causes a change in signal $V$. Dilution affects not only the concentrations of the coloured species $\left(H_{c}\right)$ but also the number of scattering particles per volume $\left(H_{t}\right)$.

From the equation $V=I_{0} H_{\text {tot }}$,

$\frac{\mathrm{d} V}{\mathrm{~d} v}=I_{0} \frac{\mathrm{d} H_{\mathrm{tot}}}{\mathrm{d} v}=\frac{I_{0} \mathrm{~d} H_{\mathrm{tot}} \mathrm{d} H_{\mathrm{c}} H_{\mathrm{t}}}{\mathrm{d} H_{\mathrm{c}} H_{\mathrm{t}} \mathrm{d} v}=I_{0} H_{\text {tot }} \frac{\dot{\alpha} H_{\mathrm{c}} H_{\mathrm{t}}}{H_{\mathrm{c}} H_{\mathrm{t}} \mathrm{d} v}=I_{0} H_{\mathrm{tot}}\left(\frac{\mathrm{d} H_{\mathrm{t}}}{H_{\mathrm{t}} \mathrm{d} v}+\frac{\mathrm{d} H_{\mathrm{c}}}{H_{\mathrm{c}} \mathrm{d} v}\right)$

The effect of the turbidity $\mathrm{d} H_{\mathrm{t}} / \mathrm{d} v$ can be rewritten by using eqn. (3): $\mathrm{d} H_{\mathrm{t}} / \mathrm{d} v$ $=\left(\mathrm{d} H_{t} / \mathrm{d} n\right) \cdot(\mathrm{d} n / \mathrm{d} v)=-K_{t} H_{t} n / v$. This leads to the same conclusion that was reached for turbidity; thus eqn. (5) can be simplified to:

$\mathrm{d} V / \mathrm{d} v=I_{0} H_{\text {tot }} \mathrm{d} H_{\mathrm{c}} / H_{\mathrm{c}} \mathrm{d} v$

If there is no shift in the chemical equilibrium involved, $\epsilon$ is independent of the concentration of the species to be detected. Thus

$\mathrm{d} H_{\mathrm{c}} / \mathrm{d} v=\left(\mathrm{d} H_{\mathrm{c}} / \mathrm{d} c\right) \cdot(\mathrm{d} c / \mathrm{d} v)$

where $c=m / v$. From eqns. $(5-7)$ in conjunction with the setpoint situation $H_{\text {tot1 }}=H_{\text {tot2 }}$, it is possible to derive the equations:

$\mathrm{d} V / \mathrm{d} v=I_{0} H_{\text {tot }} \epsilon l c / v$ and $\mathrm{d} U / \mathrm{d} v=I_{0} H_{\text {tot }}\left(K_{\mathrm{cl}}-K_{\mathrm{c} 2}\right)$ in which $K_{\mathrm{c}}=\epsilon l c / v$.

If the setpoint is properly chosen, $K_{\mathrm{c} 1}=K_{\mathrm{c} 2}$ and $\mathrm{d} U$ is independent of dilution.

In the system involved, dilution actually causes a shift in the chemical equilibrium and so the absorbance depends on the experimental conditions. It was shown, however, that the effect of dilution is negligible in comparison to the effect of sulphate addition. The experimental data proved that the dilution effect was less than $0.5 \%$ of the signal change caused by the corresponding sulphate addition.

On account of the above considerations, the block scheme of Fig. 3 was simplified to that presented in Fig. 4(a), which gives the non-linear function between $U$ and $C_{\mathrm{SO}_{4}}$ shown in Fig. $4(\mathrm{~b})$.

MODEL OF THE FLOW-THROUGH TITRATION SYSTEM

To establish a realistic model of a complete flow-through titration system, several processes must be considered; these are presented as functional blocks in Fig. 5. The first block is self-explanatory. The detection block involves 

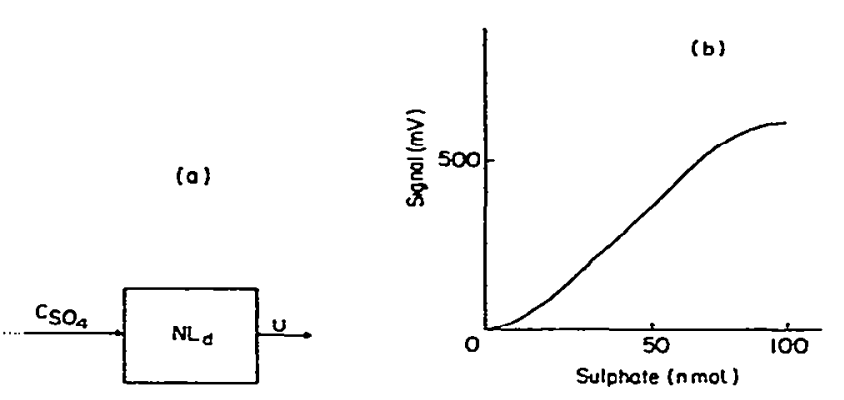

Fig. 4. (a) Simplified block scheme of the titrimeter. (b) Non-linear function representing the detector response on addition of sulphate to $8 \mathrm{ml}$ of setpoint solution in the titration cell.

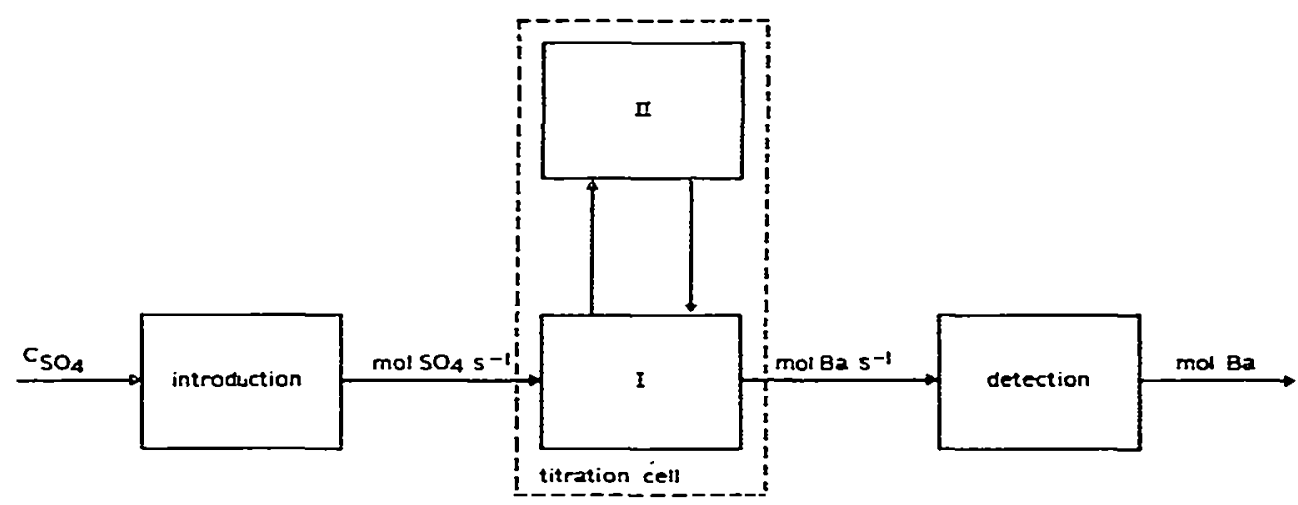

Fig. 5. Functional block scheme of the flow-through titrimeter (for explanation see text).

the non-linear function of Fig. 4(b) representing the extended model of Fig. 3 and the titrant addition. The process in the titration cell, within the dashed lines in the block scheme, is more difficult to describe. The transfer function is affected by the mixing efficiency and the rate of the chemical reaction. Block I accounts for the flow-through behaviour and the precipitation process. Block II accounts for the effects which determine the rate of the precipitation process. These transfer functions cannot be measured independently because the transfer function of the detector is always present. It is assumed that in the transfer functions of detection and electronic amplification, the dynamic part may be neglected because of relatively fast response.

Several factors are involved in the reaction rate of the titration process, e.g. the apparent $\mathrm{pH}$, the water content of the setpoint solution and the active surface of the precipitated barium sulphate which assists further nucleation. In the first attempt at modelling, the influence of the nature and amount of barium sulphate in the titration cell was studied, because the other factors can be kept constant whereas the barium sulphate precipitate varies. 
Qualitative description of the precipitation process

From several measurements of the dynamic behaviour of the system on addition of sulphate, it was found that the presence of freshly prepared barium sulphate accelerated the rate of further precipitation of barium sulphate. Relatively large amounts of aged barium sulphate had the same effect. These findings are in agreement with generally accepted theories. Because the setpoint solution is saturated with barium sulphate and the excess of barium ions is high, the reaction rate is not primarily dependent on the sulphate concentration. However, as the reaction is not homogeneous, the number of active sites on which the precipitate is formed governs the reaction rate. This number of active sites decreases with time. The use of an average value of the time constant is not permissible in modelling because the number of active sites available during the titration is variable.

A qualitative description of the processes observed is given in Fig. 6 . When a sulphate-containing sample enters the cell, the reaction rate is low, depending on the amount of barium sulphate. The period before $t_{1}$ describes the aging of the precipitate present. If this precipitate is relatively fresh (some minutes old) the number of active sites is such that upon sulphate addition (at $t_{1}$ ) precipitation starts. As the titration proceeds, with formation of the first precipitate, the number of active sites increases $\left(t_{2}\right)$. Cluster formation retards this process and when the addition of sulphate is stopped, cluster formation causes a drop in the number of active sites $\left(t_{3}-t_{4}\right)$. Finally the rate of decrease of the number of active sites is about the same as before $t_{1}$. The process is thus essentially non-linear.

\section{Qualitative modelling}

The final model tested is presented in Fig. 7. In the introduction model, the sample reaches the cell after a lapse of time which may be calculated from the system dimensions and flow rates. The duration of introduction is given by $T_{\mathrm{d}}$. Since the introduction time is rather long, the sample introduction can be assumed to be block-shaped; the height of the block at the output of the introduction system depends on the flow of the sample line and the sulphate concentration of the sample. After $T_{\mathrm{d}}$ seconds, this height becomes zero because of the transfer function $H=\exp \left(-p T_{\mathrm{d}}\right)$.

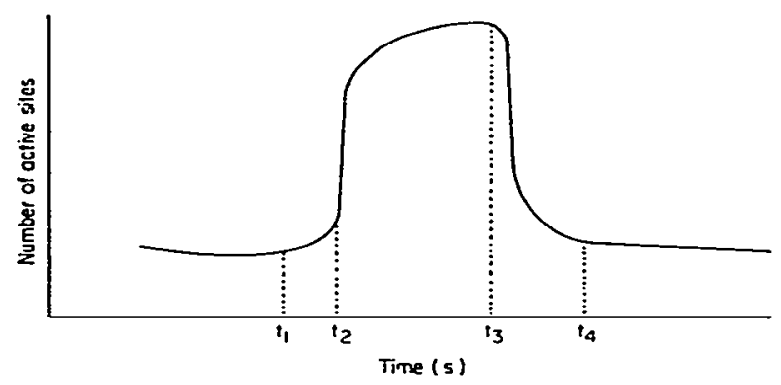

Fig. 6. Visualization of the number of active sites during the titration process. 

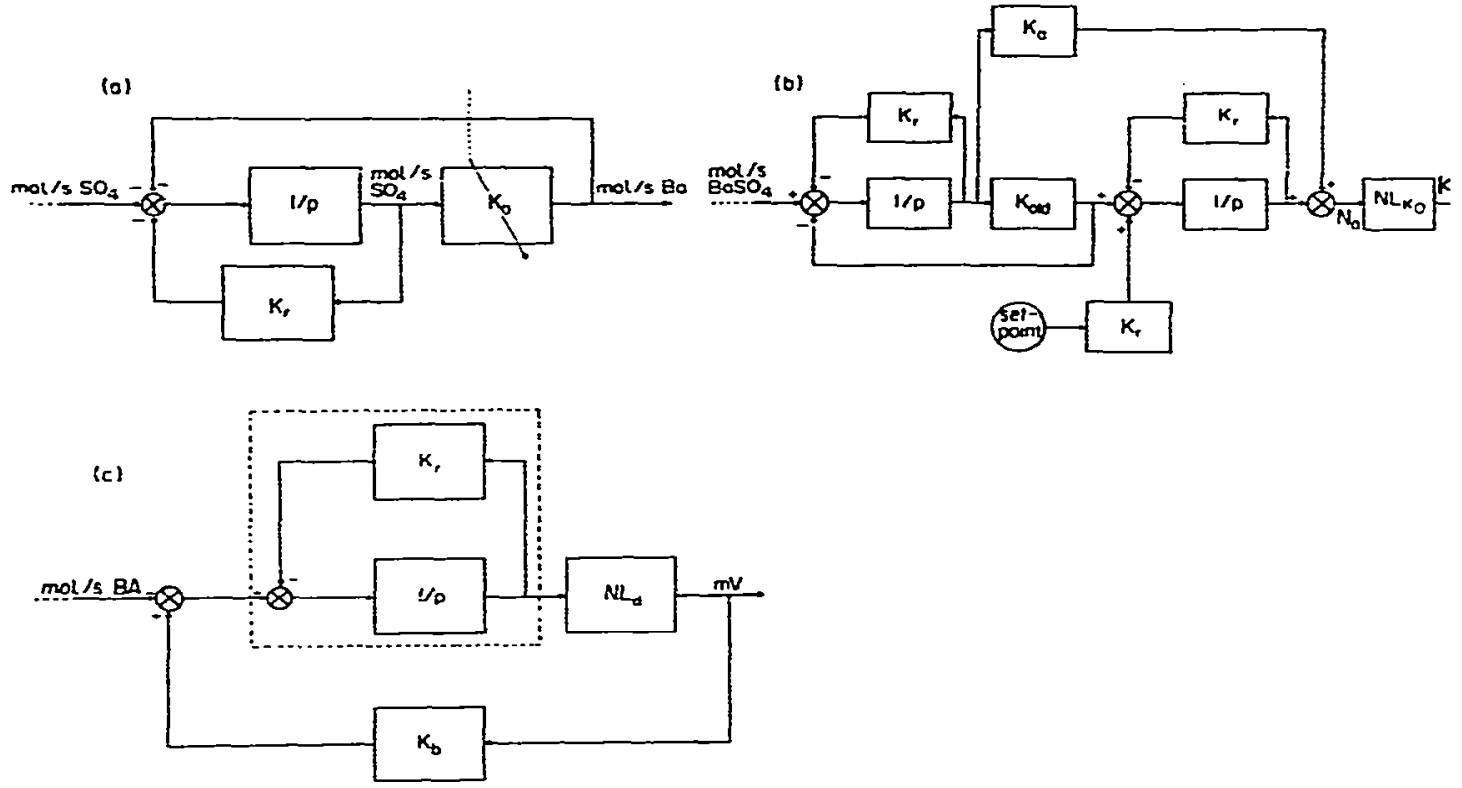

Fig. 7. (a) Block scheme of the model of the titration process. (b) Block scheme of the model of the process of formation of active sites. (c) Block scheme of the model of the detection system.

The process in the titration cell is represented in Fig. 7(a). The titration cell acts as an integrator $(H=1 / p)$ on introduction of sulphate. The amount of free sulphate ions inside the cell will decrease because of two effects: (i) the sulphate reacts with the barium ions present or added ( $\left.K_{0}\right)$ and (ii) the effluent from the cell will contain unreacted sulphate $\left(K_{r}\right)$. The amount of sulphate removed is proportional to the quotient of flow rate through the cell and the cell content. The replacement factor $K_{r}$ is determined by system dimensions and is independent of the reaction rate process. The replacement may cause a systematic error, which should be low so that the ratio between $K_{\mathrm{r}}$ and the reaction rate $K_{0}$ must be low $\left(K_{0} \gg K_{\mathrm{r}}\right)$.

The model in Fig. 7(b) accounts for the formation of active sites which influences the precipitation process of barium sulphate. The output of this model determines the value of $K_{0}$. Based on the chemical reasoning outlined above, this model includes the effects caused by old and fresh barium sulphate. The total amount of barium sulphate determines the number of active sites $\left(N_{\mathrm{a}}\right)$. However, the contribution of fresh barium sulphate to the number of active sites is larger than that of old barium sulphate. $K_{\mathrm{a}}$ is the ratio between these contributions. The relation $\left(N L_{K_{0}}\right)$ between $K_{0}$ and the number of active sites $\left(N_{\mathrm{a}}\right)$ is given by

$K_{0}=1 /\left(K_{\mathrm{M}}+K_{\mathrm{N}} / N_{\mathrm{a}}\right)$ 
where $K_{M}$ represents the maximum reaction rate and the factor $K_{N}$ defines the influence of $N_{\mathrm{a}}$ on $K_{0}$. In Fig. $7(\mathrm{~b}), K_{\text {old }}$ accounts for the effect of aging. Naturally, the amount of fresh barium sulphate decreases with time. Finally it is assumed that all barium sulphate formed on introduction of sulphate into the titration cell is fresh barium sulphate.

The model of the detection system is given in Fig. 7(c). The non-linear element $N L_{\mathrm{d}}$ has been indicated in Fig. 4(b). As this function was determined under static conditions, the input $C_{\mathrm{SO}_{4}}$ can be replaced by $C_{\mathrm{Ba}}$. The part of Fig. 7(c) boxed in dashed lines accounts for the flow-through aspect by which the cell content, including unreacted barium ions are continuously pumped off. The output signal of the burette is fed back via $K_{b}\left(K_{b}=\right.$ burette constant) to the input of the cell.

\section{Quantitative modelling}

The models indicated above were used in establishing the final model in Fig. 8. Most of the constants of the model could be calculated from the system dimensions or the results of static measurements. The values given in the blocks are based on the dimensions used ( $\mu \mathrm{l}, \mathrm{mV}, \mathrm{nmol}$ and $\mathrm{s}$ ). In order to introduce the dynamic behaviour of the precipitation process in the presence of barium sulphate into the model, $K_{\text {old }}, K_{\mathrm{a}}$ and $K_{\mathrm{N}}$ had to be estimated. This was done by fitting simulated [8] responses with two responses of the

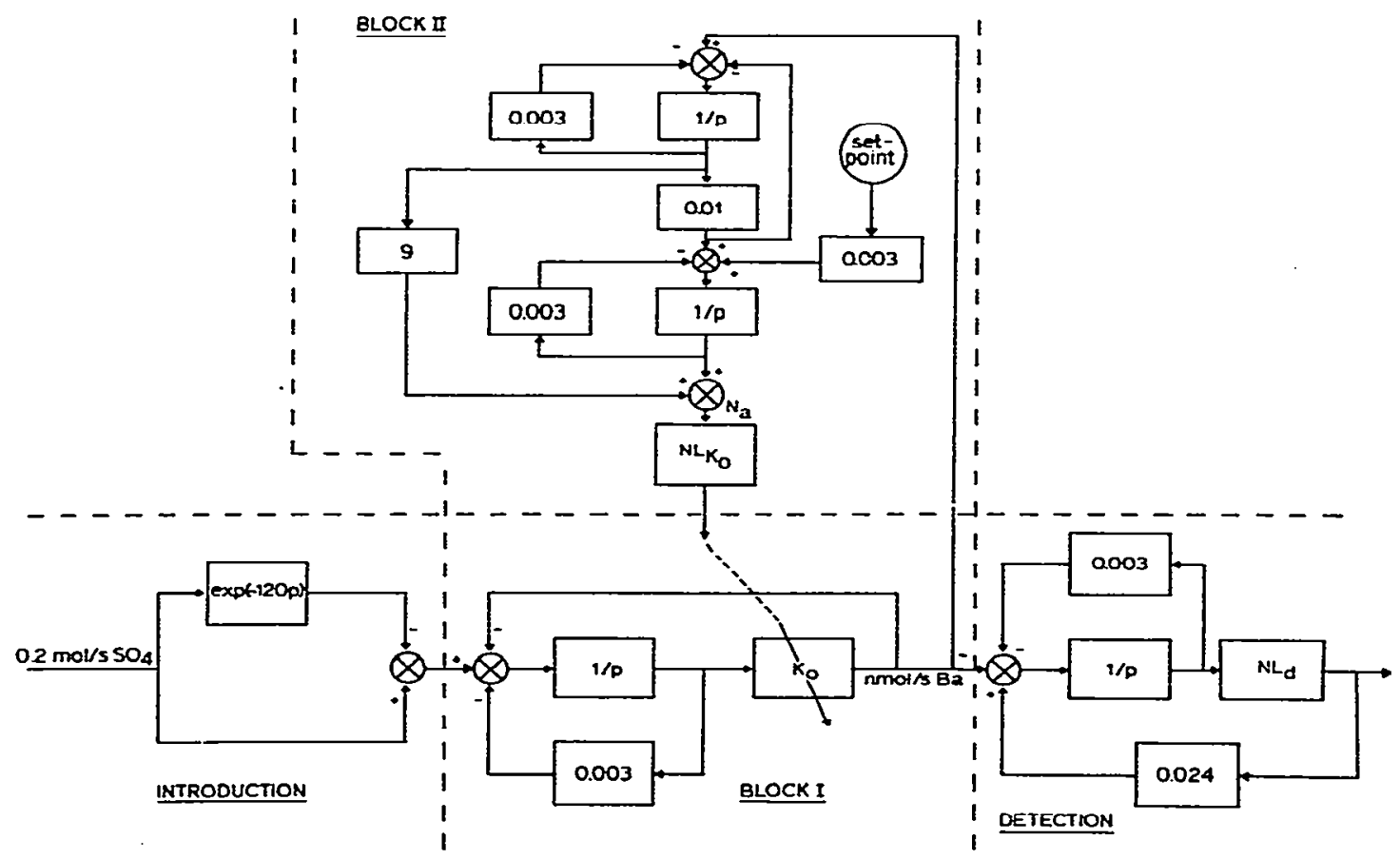

Fig. 8. Block scheme of the model of the flow-through titration. 
flow-through titrimeter obtained on continuous addition of $0.2 \mathrm{nmol} \mathrm{SO}_{4}{ }^{2-} \mathrm{s}^{-1}$ during $60 \mathrm{~s}$ using the model of Fig. 8 and adjusting $K_{\text {old }}, K_{\mathrm{a}}$ and $K_{\mathrm{N}}$. The setpoint solution contained $20 \mathrm{nmol}$ of barium sulphate. Curve 2 of Fig. 9(a) presents the measured response. Then after $200 \mathrm{~s}$, the sulphate was titrated, the burette disconnected and the same sulphate addition repeated; this gave curve 1. The steeper part at the beginning of curve 1 is explained by the presence of freshly precipitated barium sulphate and an extra amount of old barium sulphate. The fitted responses simulated by the computer are presented as dotted lines.

\section{DISCUSSION AND RESULTS OF SIMULATION}

It was found that $K_{\mathrm{a}}$ depends on the method of preparation of the setpoint solution. Although the solutions were prepared as reproducibly as possible, variation in $K_{\mathrm{a}}$ may be introduced. The values of $K_{\text {old }}, K_{\mathrm{a}}$ and $K_{\mathrm{N}}$ found by curve fitting lead to the following conclusions: (i) the time constant of the aging process is about $100 \mathrm{~s}$; (ii) fresh barium sulphate provides 10 times more active sites than the old precipitate; (iii) the change of reaction rate on the change of the number of active sites is in the region of $4 \times 10^{-4} \mathrm{~mol} \mathrm{~s}^{-1}$.

The model was first used to predict the response of the flow-through titrimeter upon two successive titrations of $25 \mathrm{nmol}$ of sulphate in the presence of $20 \mathrm{nmol}$ of barium sulphate in the titration cell originating from the setpoint solution. For the second titration, which was carried out $300 \mathrm{~s}$ after the first one, the remaining barium sulphate formed during the first titration is added to the $20 \mathrm{nmol}$ of barium sulphate from the setpoint solution. To simulate the second titration the initial amounts of fresh and old barium sulphate are corrected for the remaining amounts of these species formed during the first titration. In Fig. 9(b) the simulated curves are indicated by dotted lines: curve 1 represents the first titration and curve 2 the second one. The
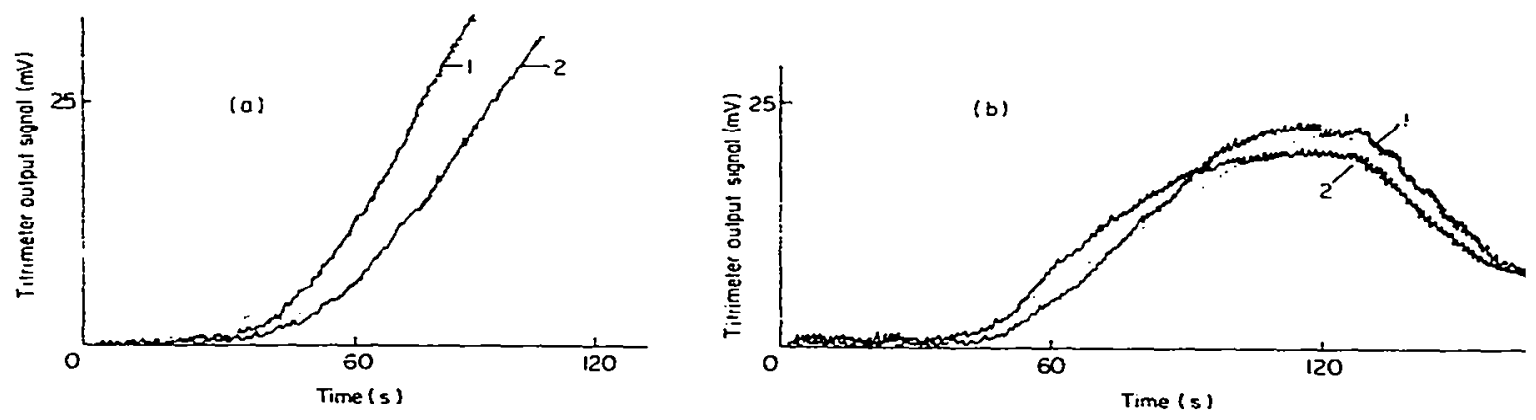

Fig. 9. Comparison of simulated (dotted lines) and experimental responses. (a) For continuous introduction of $0.2 \mathrm{nmol} \mathrm{SO}_{4}{ }^{2-} \mathrm{s}^{-1}$ in the presence of $20 \mathrm{nmol}$ of $\mathrm{BaSO}_{4}:$ (1) $200 \mathrm{~s}$ after the first titration was carried out; (2) before any titration. (b) For titration of 25 nmol of sulphate in the presence of $20 \mathrm{nmol}$ of $\mathrm{BaSO}_{4}:$ (1) the first titration; (2) $300 \mathrm{~s}$ after the first titration. 
recoveries, defined as the ratio between sulphate found by titration and given sulphate, obtained by simulation of the titrations were $82 \%$ and $84.5 \%$, respectively. Real experiments carried out under the same circumstances as used for simulation gave recoveries of $86 \%$ and $92 \%$, respectively.

The same model was used to simulate the response on introduction of 0.2 nmol $\mathrm{SO}_{4}{ }^{2-} \mathrm{s}^{-1}$ during $70 \mathrm{~s}$ in the presence of $100 \mathrm{nmol}$ of barium sulphate. The only adaptation in the model was the adjustment of the value of the setpoint (Fig. 7b). Figure 10(a) shows the simulated (dotted line) and real response. The model was also used to simulate a titration of $25 \mathrm{nmol}$ of sulphate in the presence of $100 \mathrm{nmol}$ of barium sulphate; the simulated and real curves are shown in Fig. 10(b). The recovery found by simulation was $90 \%$; real measurements gave a recovery of $96 \%$.

Although on titration of $25 \mathrm{nmol}$ of sulphate in the presence of $20 \mathrm{nmoi}$ of barium sulphate the agreement between real and predicted curves is not complete, the simulated response predicts the relation between the slopes and the maximum values sufficiently. The behaviour of the response obtained with the real system at the beginning may be caused by a slight deviation from the setpoint. The other simulated and real responses show good conformity.

Figure 11 presents the reaction rate curves corresponding to the simulated titration curves of Figs. $9(\mathrm{~b})$ and $10(\mathrm{~b})$. The simulation indicates that the improvement of the recovery is caused mainly by the higher initial value of the reaction rate $\left(K_{0}\right)$. Another way of achieving a higher value of $K_{0}$ is to form fresh barium sulphate continuously in the titration cell. This may be accomplished by a continuous inflow of sulphate solution into the cell. The simulation of such a system on continuous introduction of sulphate at a rate of $0.2 \mathrm{nmol} \mathrm{s} \mathrm{s}^{-1}$ to the titration cell indicated a recovery of $98 \%$. This has not yet been verified in practice because the equipment required is not available.
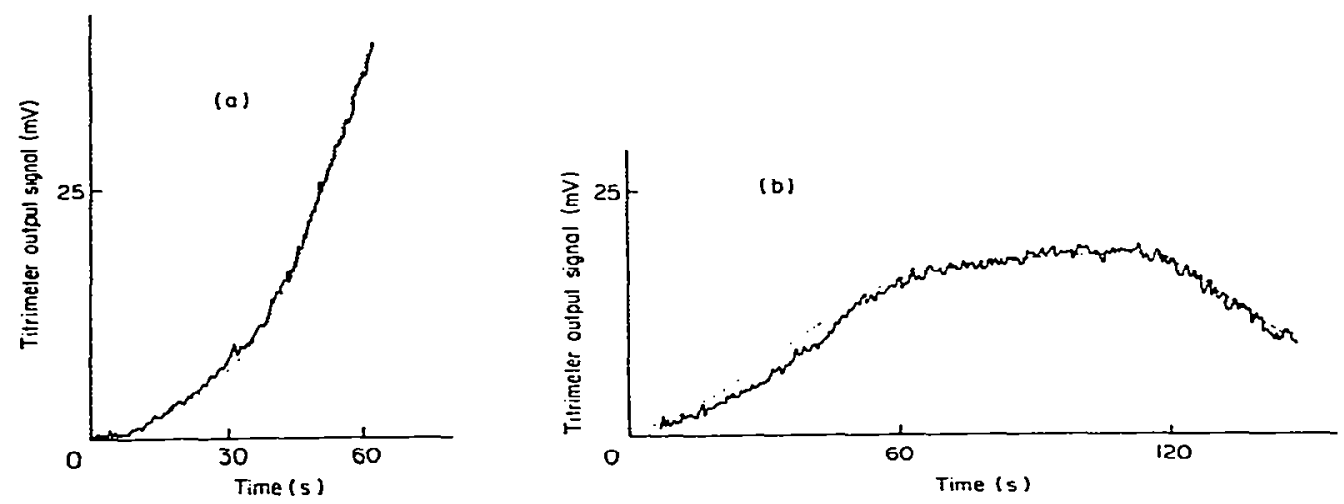

Fig. 10. Comparison of simulated (dotted line) ard experimental responses. (a) For continuous introduction of $0.2 \mathrm{nmol} \mathrm{SO}{ }_{4}{ }^{2-} \mathrm{s}^{-1}$ in the presence of $100 \mathrm{nmol}$ of $\mathrm{BaSO}_{4} ;(\mathrm{b})$ for titration of $25 \mathrm{nmol}$ of sulphate in the presence of $100 \mathrm{nmol}$ of $\mathrm{BaSO}_{4}$ - 


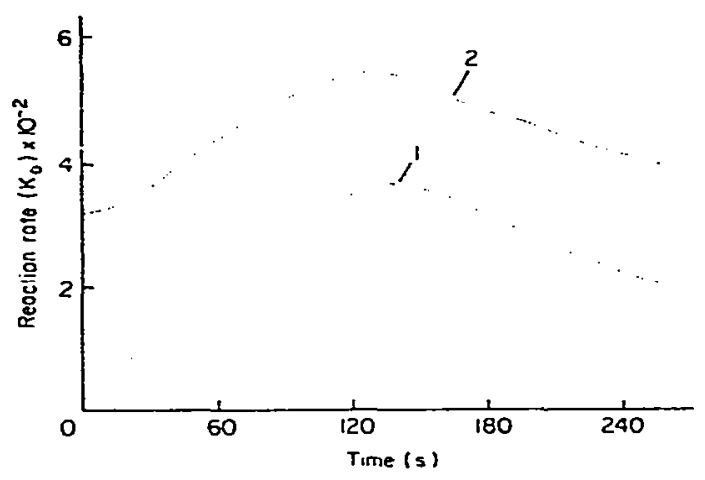

Fig. 11. Reaction rate curves on titration of $25 \mathrm{nmol}$ of sulphate in the presence of (1) 20 $\mathrm{nmol}$ of $\mathrm{BaSO}_{4}$ and (2) $100 \mathrm{nmol}$ of $\mathrm{BaSO}_{4}$.

\section{Conclusion}

The effects of the various physical parameters on the signal of the titrimeter have been calculated. Dilution effects are negligible compared with the effect of sulphate addition. These calculations were confirmed by experiment.

The model developed predicts the behaviour of the tested system well. The simulations indicate that the reaction rate of the precipitation of barium sulphate is about 5 times higher with fresh barium sulphate than with old precipitate. It is concluded from the simulations that the recovery is improved by increasing the amount of barium sulphate in the setpoint solution. This conclusion was confirmed by experiment.

This paper shows the basic ideas necessary for describing flow-through titrimetric systems, which will ease the modelling of other flow-through systems. The models obtained may be used to optimize flow-through systems with respect to accuracy, recovery and titration rate.

\section{REFERENCES}

1 G. H. B. Eelderink, H. B. Verbruggen, F. A. Jutte, W. J. van Oort and B. Griepink, Fresenius Z. Anal. Chem., 280 (1976) 273.

2 W. Jongkind, G. H. B. Eelderink, H. B. Verbruggen, W. J. van Oort and B. Griepink, Fresenius Z. Anal. Chem., 286 (1977) 76.

3 G. Veenendaal, F. A. Jutte, G. H. B. Eelderink, H. B. Verbruggen, W. J. van Oort and B. Griepink, Fresenius Z. Anal. Chem., 285 (1977) 337.

4 H. F. R. Reijnders, J. J. van Staden, G. H. B. Eelderink and B. Griepink, Fresenius Z. Anal. Chem., 292 (1978) 290.

5 H. F. R. Reijnders, J. J. van Staden and B. Griepink, Fresenius Z. Anal. Chem., 293 (1978) 413.

6 W. Jongkind, G. H. B. Eelderink, H. B. Verbruggen, W. J. van Oort and B. Griepink, Fresenius Z. Anal. Chem., 286 (1977) 72.

7 W. J. van Oort, P. C. Schalkwijk, R. A. Brandenburg and B. Griepink, Fresenius Z. Anal. Chem., 276 (1975) 181.

8 P. P. J. van den Bosch, Proceedings of the IF AC symposium on computer aided design of control systems, Zürich, 1979. 